American Journal of Neuroscience 2 (1): 28-34, 2011

ISSN 1948-9900

C 2011 Science Publications

\title{
Clinical and Functional Profile of Amyotrophic Lateral Sclerosis Patients: A one Year Follow up
}

\author{
1,2 Marco Orsini, ${ }^{1}$ Marcos R.G. de Freitas, ${ }^{1}$ Osvaldo J.M. Nascimento, \\ ${ }^{3}$ Acary Bulle Oliveira, ${ }^{1}$ Marco Antonio Araujo Leite, ${ }^{1}$ Giseli Quintanilha,

\begin{abstract}
Problem statement: Amyotrophic Lateral Sclerosis (ALS) is a progressive and degenerative disease that affects the anterior horn motor neurons of the spinal cord and pyramidal tracts. In Brazil, there are few epidemiological data on this disease. Recently, some important findings have been reported, allowing a better understanding on the underlying processes of neuronal death, as well as the characteristics of this population. To discuss the clinical and functional profile of a convenience sample of patients with ALS in Rio de Janeiro and Neurology Department-Federal Fluminense University to compare the data with studies of other regions and countries. Approach: We used the Severity and Functional Ability Scale (SFAS) as a clinical and functional indicator for ALS. The modified El Escorial criteria were used to establish the diagnosis. The participants underwent five quarterly assessments during the study period. The research took place at two University Hospitals (Hospital Universitario Antonio Pedro-Universidade Federal Fluminense and Instituto de Neurologia Deolindo Couto-Universidade Federal do Rio de Janeiro) from March 2007 to December 2009. Results: Of the 98 recruited subjects, only 24 have completed all phases of the study. The average age was $52.7 \pm 4.1$ years. The time between the onset of first symptoms and seeking care services was 11.6 $\pm 12 .: 4$ months. The time between the first symptoms and the diagnosis was 20.5 \pm 8.4 months. Muscle weakness was identified as the initial symptom in most cases. Patients had impaired muscle strength, speech, swallowing, respiratory function and severity stages of SFAS. The disease had different forms of initial presentation (impaired speech, limbs strength, respiratory function or swallowing), time to progression and clinical characteristics in our population. Conclusion: The knowledge on the individual clinical evolution in ALS is of paramount importance for the healthcare team to provide a correct treatment during the decline of
\end{abstract}

Corresponding Author: Marco Orsini, Department of Neurology and Federal, Fluminense University (UFF), Rua Herotides De Oliveira, 2/apto. 801. Jardim Icarai, CEP 24230240 Niteroi-Rio de Janeiro, Brazil 
the disease and formulate theoretical and conceptual issues, aiming at solving problems in clinical practice.

Key words: Amyotrophic lateral sclerosis, motor neuron, epidemiology, Severity and Functional Ability Scale (SFAS), pathophysiologic processes, scientific literature, functional limitations, epidemiological data

\section{INTRODUCTION}

In the last years, many professionals have sought to systematically evaluate multiple aspects of their patients' health as a way to set more effective interventions and research. This process requires a complex understanding of the natural history of the disease as well as an overview of the imposed clinical and functional limitations (Sampaio et al., 2002; Williams et al., 1997). The lack of epidemiological data related to motor neuron diseases and especially to Amyotrophic Lateral Sclerosis (ALS) is due to its short evolution time and the inexorable fatal outcome. Several genetic, environmental and endogenous factors seem to contribute to the onset and progression of neurotoxicity in the disease. These factors can be mediated by multiple mechanisms: free radicals, including nitric oxide, intracytoplasmic protein aggregates, Fas/Fas ligand-mediated death pathway, aberrant neurofilament accumulation, glutamatemediated excitotoxicity, abnormal retrograde axonal transport and neurotrophic factor disability (Voltarelli, 2004; Gordon, 2011). Despite this, the underlying pathophysiologic processes of ALS are still unknown.

Thus, this study aimed to describe the clinical and functional characteristics of ALS patients as a way to help the healthcare professionals in the establishment of realistic goals. We also performed comparisons on possible predictive factors for ALS based on the current scientific literature.

\section{MATERIALS AND METHODS}

This was a cross-sectional study, with a convenience sample. The research was conducted in the Neurology Service of the Hospital Universitário Antônio Pedro (HUAP-Universidade Federal Fluminense) and in the Instituto de Neurologia Deolindo Couto (INDC-Universidade Federal do Rio de Janeiro). The participants underwent five quarterly assessments (done by the same researcher) over a period of one year (0-3-6-9-12 months), using the Severity and Functional Ability in ALS (Orsini et al., 2008; 2009). Data collection took place in an acclimatized room, protected from external noise and with a floor suitable for a scientific evaluation. Each evaluation lasted 50 minutes in average and according to the patients' needs, pauses between 10-15 min breaks were provided.

For inclusion in the study, patients had to present: diagnosis of ALS, probable or probable with laboratory support by the criteria of the World Federation of Neurology (revised in 2000-Criteria for EL Escorial) (Brooks et al., 2000) and age between 40-85 years. Subjects presenting at least one of the following characteristics were not included: patients who did not attend the four pre-established assessments; electroneuromyography demonstrating sensory or motor conduction block; depression or emotional instability that could compromise the patients' participation; pain, muscle retractions or associated problems that could prevent the manual muscle testing; spasticity greater than or equal to 2 in the modified Ashworth scale (Damiano et al., 1999); other comorbidities. The project was approved by the institutional ethics committee (number 4505004-2007) and all participants signed an informed consent term. Statistical analysis used the SPSS software (Version 10.0; SPSS, Inc., Chicago, IL, USA).

\section{RESULTS}

From March 2007 to December 2009, 49 men and 49 women were admitted to the study. The average age of the recruited patients was $52.7 \pm 12$ years. The average time between the onset of symptoms and demand for care services was $11.6 \pm 12.4$ months.

Of the 98 subjects evaluated only 24 finished all stages of the study. The sample losses had been given by death $(\mathrm{n}=30)$, not completion of all the stipulated stages $(\mathrm{n}=21)$ and voluntary evasion $(\mathrm{n}=23)$, this mainly because of displacement difficulties. The remaining 24 subjects (14 men and 10 women) were $53.3 \pm 12$ years old. The average time between the first symptoms and the diagnosis was $20.5 \pm 8.4$ months. The site of first symptoms was the upper limbs in 32 patients and lower limbs in 43 patients. Sixteen subjects presented speech difficulties in the beginning of the disease, whilst swallowing was the main problem for seven patients. 
Am. J. Neuroscience 2(1): 28-34, 2011

Table 1: Evaluation of muscle strength (average) during 1-year study graduation maximum;:100 points; minimum graduation: 0 points

\begin{tabular}{|c|c|c|c|c|c|c|c|c|}
\hline & \multirow[b]{2}{*}{$\mathrm{N}$} & \multirow[b]{2}{*}{ Mean } & \multirow[b]{2}{*}{ Std. Deviation } & \multirow[b]{2}{*}{ Minimum } & \multirow[b]{2}{*}{ Maximum } & \multirow[b]{2}{*}{ 25th } & \multicolumn{2}{|l|}{ Percentiles } \\
\hline & & & & & & & 50th (Median) & 75th \\
\hline$\overline{\mathrm{F} 1}$ & 24 & 61.92 & 24.705 & 6 & 96 & 41.75 & 65.00 & 83.00 \\
\hline F2 & 24 & 48.58 & 24.828 & 5 & 91 & 30.50 & 49.50 & 65.00 \\
\hline F3 & 24 & 40.13 & 23.560 & 2 & 90 & 26.50 & 36.00 & 60.00 \\
\hline F4 & 24 & 32.88 & 23.350 & 0 & 90 & 19.25 & 26.50 & 48.00 \\
\hline F5 & 24 & 27.83 & 23.200 & 0 & 90 & 12.00 & 21.00 & 36.00 \\
\hline
\end{tabular}

Table 2: Descriptive measures of functional skills variable graduation maximum: 100 points; minimum graduation: 0 points

\begin{tabular}{|c|c|c|c|c|c|c|c|c|}
\hline & \multirow[b]{2}{*}{$\mathrm{N}$} & \multirow[b]{2}{*}{ Mean } & \multirow[b]{2}{*}{ Std. deviation } & \multirow[b]{2}{*}{ Minimum } & \multirow[b]{2}{*}{ Maximum } & \multirow[b]{2}{*}{25 th } & \multicolumn{2}{|l|}{ Percentiles } \\
\hline & & & & & & & 50th (Median) & 75 th \\
\hline$\overline{\mathrm{H} 1}$ & 24 & 58.54 & 33.508 & 0 & 100 & 35.00 & 70.00 & 85.00 \\
\hline $\mathrm{H} 2$ & 24 & 44.58 & 27.620 & 0 & 85 & 18.75 & 50.00 & 65.00 \\
\hline $\mathrm{H} 3$ & 24 & 37.92 & 25.406 & 0 & 85 & 12.50 & 50.00 & 50.00 \\
\hline $\mathrm{H} 4$ & 24 & 34.58 & 26.040 & 0 & 85 & 3.75 & 37.50 & 50.00 \\
\hline H5 & 24 & 30.00 & 26.906 & 0 & 85 & 0.00 & 30.00 & 50.00 \\
\hline
\end{tabular}

Table 3: Descriptive measures of swallowing variable during one year of study

\begin{tabular}{|c|c|c|c|c|c|c|c|c|}
\hline & \multirow[b]{2}{*}{$\mathrm{N}$} & \multirow[b]{2}{*}{ Mean } & \multirow[b]{2}{*}{ Std. deviation } & \multirow[b]{2}{*}{ Minimum } & \multirow[b]{2}{*}{ Maximum } & \multirow[b]{2}{*}{ 25th } & \multicolumn{2}{|l|}{ Percentiles } \\
\hline & & & & & & & 50th (Median) & 75 th \\
\hline D1 & 24 & 87.50 & 20.851 & 25 & 100 & 75.00 & 100.00 & 100.00 \\
\hline D2 & 24 & 85.42 & 20.743 & 25 & 100 & 75.00 & 100.00 & 100.00 \\
\hline D3 & 24 & 77.08 & 22.014 & 25 & 100 & 56.25 & 75.00 & 100.00 \\
\hline D4 & 24 & 72.92 & 20.743 & 25 & 100 & 50.00 & 75.00 & 93.75 \\
\hline D5 & 24 & 64.58 & 24.358 & 25 & 100 & 50.00 & 75.00 & 75.00 \\
\hline
\end{tabular}

At the beginning of the study 52 patients were under any rehabilitation treatment, 81 had begun medical treatment with riluzole, 11 were taking multivitamins and 6 natural supplements. The 24 patients who completed all the steps were followed for 12 months through five assessments, the first considered initial one and with the other quarterly reevaluations.

Regarding the muscle strength analysis during the one-year-study, significant differences were found in the depletion of muscle performance, characterizing the evolutionary process of the disease $\left(\mathrm{X}_{4: 0,05}^{2}=89.410 ; \mathrm{p}\right.$ $=0.0001)$. It is noteworthy that during the study, an average loss of muscle strength of $55.5 \%$ occurred in the subjects involved. The average degree of muscle strength in the initial assessment was 61.92 points/100points. After a 12-month follow-up the subjects showed an average decrease of 27.83 points/100 points (Table 1).

In the evaluation of the variable related to the functional abilities the results also show differences between the test moments. (X24:0, $05=57.497$; $\mathrm{p}=$ $0,000)$. In 12 months of study an average loss of 48 , $75 \%$ of the listed item occurred (Table 2 ).

The sub-items of functional abilities have scores that ranged from 0-5-10 points, characterizing respectively complete dependence, dependence and partial functional independence. With regard sub-item feeding modifications changes were found between the initial and final moments of the study $\left(\mathrm{X}_{4: 0,05}^{2}=36,459\right.$; $\mathrm{p}=0,000)$. Initially, the average was $6.25 / 10$ points. At the end of the study, the values declined to $3.13 / 10$ points. The sub-item associated with the ascending and descending stairs was one of the most committed $\left(\mathrm{X}_{4: 0,05}^{2}=28.390 ; \mathrm{p}=0.000\right)$. Initially, patients had values of $5 / 10$ points, decreasing to $2.71 / 10$ points in the last revaluation. The functional activities in the standing position were also impaired after comparison of the initial and final values $\left(\mathrm{X}_{4: 0,05}^{2}=28.626 ; \mathrm{p}=\right.$ 0.000 ). At the beginning of the study, average values were $6.04 / 10$ points and $3.54 / 10$ points at the end. In the sub-item walking or wheelchair, the subjects involved in studies initially obtained an average score of 5.83/10 points, with a significant decline at the end of the study $3.13 / 10$ points $\left(\mathrm{X}_{4: 0,05}^{2}=31.101 ; \mathrm{p}=\right.$ 0.000).

After analysis of the item deglutition changes were also found between the moments of the test. $\left(\mathrm{X}_{4: 0,05}^{2}=\right.$ 47.742; $\mathrm{p}=0.000)$. In 12 months of study, an average loss of $26.19 \%$ of the above-mentioned function occurred. It is noteworthy that this analysis ranged between 0-25-50-75-100 points. The initial average of the punctuation was of $87.50 / 100$ points with reduction for $64.58 / 100$ to the ending of the last reevaluation (Table 3 ). 
Am. J. Neuroscience 2(1): 28-34, 2011

Table 4: Descriptive measures breathing variable during one year of study

\begin{tabular}{|c|c|c|c|c|c|c|c|c|}
\hline & \multirow[b]{2}{*}{$\mathrm{N}$} & \multirow[b]{2}{*}{ Mean } & \multirow[b]{2}{*}{ Std. Deviation } & \multirow[b]{2}{*}{ Minimum } & \multirow[b]{2}{*}{ Maximum } & \multirow[b]{2}{*}{25 th } & \multicolumn{2}{|l|}{ Percentiles } \\
\hline & & & & & & & 50th (Median) & 75 th \\
\hline$\overline{\mathrm{R} 1}$ & 24 & 91.67 & 15.926 & 50 & 100 & 81.25 & 100.00 & 100.00 \\
\hline R2 & 24 & 86.46 & 18.027 & 50 & 100 & 75.00 & 100.00 & 100.00 \\
\hline R3 & 24 & 82.29 & 18.765 & 50 & 100 & 75.00 & 75.00 & 100.00 \\
\hline $\mathrm{R} 4$ & 24 & 78.13 & 21.255 & 50 & 100 & 50.00 & 75.00 & 100.00 \\
\hline R5 & 24 & 72.92 & 22.014 & 50 & 100 & 50.00 & 75.00 & 100.00 \\
\hline
\end{tabular}

Table 5: Descriptive measures of variable stages of disease ranking of disease stages: Stage 1: Initial disease; Stage 2: Mild dependence; Stage 3: Moderate Dependence; Stage 4: Severe Dependence; Stage 5: Stage of Terminal Illness. * Maximum score obtained on the instrument $=4$

\begin{tabular}{|c|c|c|c|c|c|c|c|c|}
\hline & \multirow[b]{2}{*}{$\mathrm{N}$} & \multirow[b]{2}{*}{ Mean } & \multirow[b]{2}{*}{ Std. Deviation } & \multirow[b]{2}{*}{ Minimum } & \multirow[b]{2}{*}{ Maximum } & \multirow[b]{2}{*}{25 th } & \multicolumn{2}{|l|}{ Percentiles } \\
\hline & & & & & & & 50th (Median) & 75th \\
\hline$\overline{\text { E1 }}$ & 24 & 1.63 & 0.824 & 1 & 4 & 1.00 & 1.00 & 2.00 \\
\hline E2 & 24 & 2.08 & 0.881 & 1 & 4 & 1.25 & 2.00 & 2.75 \\
\hline E3 & 24 & 2.54 & 0.884 & 1 & 4 & 2.00 & 3.00 & 3.00 \\
\hline E4 & 24 & 2.83 & 0.868 & 1 & 4 & 2.00 & 3.00 & 3.00 \\
\hline E5 & 24 & 3.13 & 0.992 & 1 & 5 & 3.00 & 3.00 & 4.00 \\
\hline
\end{tabular}

After consideration of the item breathing, differences were found between the moments of the test. $\left(\mathrm{X}_{4: 0,05}^{2}=38.470 ; \mathrm{p}=0.000\right)$. In 12 months of study, an average loss of $20.45 \%$ happened in this function. It is noteworthy that this analysis ranged between 0-25-50-75-100 points. The initial mean score was $91.67 / 100$ points and decrease to $72.92 / 100$ at the end of the last review (Table 4).

Regarding to the analysis of specific severity stages of the instrument, being stage 5 considered the final stage and stage 1 the onset of the disease, there was a significant evolution between the severity levels that had passed from 1.63 to 3.13 over a period of one year study. $\left(X_{4: 0,05}^{2}=67.701 ; p=0.000\right)$. After 12 months of study there was an evolution of the disease, with average values characterizing worsening of $92 \%$. Initially, patients had average values of 1.63 (stage), getting progressively worse after the last reassessment, 3.13 (stage) (Table 5).

Table 5 Descriptive measures of variable stages of disease. Ranking of disease stages: Stage 1: Initial disease; Stage 2: Mild dependence; Stage 3: Moderate Dependence; Stage 4: Severe Dependence; Stage 5: Stage of Terminal Illness. * Maximum score obtained on the instrument $=4$.

\section{DISCUSSION}

ALS is a neurodegenerative disease that affects the motor nervous system, causing progressive and cumulative physical impairment, with death often resulting from respiratory failure about five years after the onset of first symptoms. The disease has several features in the different presentation forms, course and progression (Orsini et al., 2010). Our results showed rapid depletion of functional capacity, muscle strength, swallowing and breathing pattern, corroborating the considerations described above. The onset of ALS is often insidious and can manifest by unexplained trip or motor disabilities, usually in the distal arm. Some patients with bulbar onset have difficulty in swallowing and changes in voice tonality. Many patients are diagnosed about 12 months after the beginning of first symptoms (Oliveira and Pereira, 2009). These results are in agreement with those obtained in the present study, considering that the average time between the onset of symptoms and demand for healthcare services was $11.57 \pm 12.4$ months.

Many of our patients declared that they postponed visit to experts because they believed that the initial problems presented were transient or associated with specific activities. Some sought generalist doctors whom had affirmed to ignore such symptoms. Since the moment the diagnosis of ALS is considered possible, patients are submitted to numerous laboratory tests. This factor contributes to the delay between the start of the first symptoms and diagnosis. This problem was also pointed out in other studies (Kraemer et al., 2010; Traynor et al., 2000).

Dengler (1999) demonstrates that the findings related to ALS presentation in the subgroup of European countries (Italy, Germany, Spain) have some similarity with the characteristics of other industrialized countries as, for example, in Brazil. According to this author, the age of beginning of symptoms is around 5059 years (26\% of patients) and 60-69 years $(27 \%$ of patients). About $39 \%$ of patients are women. The majority $(82 \%)$ had spinal cord involvement (members), while the remaining (approximately 18\%) starts the clinical course of the disease with bulbar 
involvement. Such considerations are in accordance to the average age of the patients of this study: 52.7 years \pm 12 years. We found no predominance of the disease in relation to gender. Of the 98 patients initially included in the study, 32 presented the first complaints in the upper limbs and 43 in the lower limbs. Sixteen subjects began with disease problems in speech and seven with swallowing difficulties, with frequent choking, especially with liquids.

Rodriguez et al. (2009) when evaluating 148 patients with ALS found a medullar and bulbar beginning in 70.9 and $29.1 \%$ of the sample, respectively. The most frequent abnormality was muscle weakness in lower limbs $(24.7 \%)$, followed by motor disabilities in the upper limbs (26.2\%). Twenty nine patients of our study had initiated the clinical presentation with less frequent complaints such as pain, muscle atrophy and fasciculations. Tartaglia et al. (2007) also presented data that coincide with those listed above.

Chio et al. (2009) emphasize that the median survival time from the beginning of the first symptoms to death was in average $20-40$ months. However the authors stress that about $10-20 \%$ of these patients survive for more than 10 years. Older age at diagnosis and bulbar onset contribute to a poor prognosis. Unfortunately, these findings could not be extracted from the present study by numerous problems. The follow-up interruption of 74 patients, either by withdrawal or death contributed to such. Moreover, many patients, as the disease progressed, became unable to attend the services, as needed caregivers and/or companions.

Faria et al. (2008) in a longitudinal study conducted at the Federal University of São Paulo, traced the clinical profile of 20 patients with motor neuron disease. The presentation of the first symptom as muscle weakness was reported by $45 \%$ of the sample. Other studies show even more expressive results, with $72 \%$ of patients presenting it as a initial symptom (Alcaz et al., 1996; Zoccolella et al., 2006). Undoubtedly the presence of muscle weakness is directly associated with the functional impairment. Most patients in our sample reported the presence of muscle weakness as the starting point of the disease, usually characterized by motor disabilities in performing basic and instrumental activities of daily living.

In our study we noticed an increasing commitment of muscle strength during the 12 month follow up. Our sample had an average loss of $55.5 \%$ in muscle strength, being the average grade in the initial evaluation of $61.9 / 100$ points and of $27.8 / 100$ points in the end. Based on the current literature, Dupuis and Echaniz-Laguna (2010) defend the hypothesis, that the muscle atrophy and weakness should not be considered simply as damage caused by the depletion of neurons in the anterior horn of spinal cord. In some ALS cases, for example, part of the phenotype can be explained by pathogenic events in skeletal striated muscles. As a result, such events can be considered targeting in potential new treatment options.

The characterization of the level of functional dependency in ALS patients is essential to identify the main barriers faced and setting realistic treatment goals, including clinical rehabilitation (Orient-Lopez et al., 2006). The results of our sample indicate a significant depletion in the functional independence level during the 12 month study. All functional skills showed statistically significant results. Many patients, at the end of the study, were unable to perform basic functions such as food, clothing and transfers/changes in position. Of the group initially studied, 52 patients performed physical rehabilitation aiming at a better control of the deficiencies/disabilities caused by ALS.

Orient-Lopez et al. (2006) affirm that from the medical point of view, the care of patients with ALS must be traced on a good knowledge of illness and functional impairments, leading to an optimal provision of information to the patient and its relatives, as well as for the establishment of short, medium and long term goals. Accessibility of sanitary services, provision of technical aids, treatment of symptoms and indication of alternative methods for oral feeding, home care, as well as advice and support throughout the course of the disease should be employed. These aspects and also the integral attention, which starts from the moment of diagnosis until the terminal phase, should be provided by an interdisciplinary team.

In ALS, close to $30 \%$ of patients begin the disease with bulbar symptoms including dysphagia, dysarthria and phonatory changes. There is still no consensus about whether the commitment involves the bulbar deterioration of the three functions simultaneously or if they may have an independent evolution. There are scales to assess these individual functions, which are of difficult clinical application. The appropriate measurement of their changes allows the proper assessment of the deficiency/disability. Our data are consistent with the current literature because of the 98 initial patients in the study, 16 reported the disease beginning with problems in the speech and seven with difficulties in the deglutition (total of 33 patients), corresponding to about $29 \%$ of our sample. 
In ALS, when the ventilatory muscles are compromised the individuals present pulmonary restrictions, characterized by a decrease in Vital Capacity (VC) and Tidal Volume (TV) with consequent chronic respiratory failure. The pathophysiology of respiratory failure in neuromuscular diseases, such as ALS, is complex and may involve several inter-related factors or not. Changes in ventilation control, appearance of fatigue signals and respiratory muscular weakness, changes in mechanical properties of the respiratory system, changes in gas exchange, especially at night and upper respiratory tract dysfunction are some of the impairments found (Lemoignan and Ells, 2010).

In 12 months of study we verified the occurrence of a respiratory function loss of $20.45 \%$ in average. The initial score was $91 / 100$ points with reduction to $72 / 100$ in the last assessment. Many of our patients presented any respiratory impairment, mainly dyspnea to big and/or moderate efforts with/without increase in respiratory rate and use of the accessory muscles. However they did not need oxygen support and/or noninvasive ventilation. We noticed a tendency to withdraw in adhesion to the treatment in both the services when the patients started to need ventilatory support. It is worth notice that the association of physiotherapy with the medical approach during the course of the disease seem to improve the quality of life and reduce the respiratory complications caused by retention of secretion and loss of cough ability.

The bad prognostic in ALS makes the palliative support the last strategy for the healthcare professionals. The prognosis and treatment options should be openly discussed with patients and their relatives. Adequate assistance and palliative treatment in terminal phase are of primordial importance. Unfortunately, training directed for young doctors and evidence based recommendations for palliative care, are still insufficient (Borasio, 2001; Stanich, 2006; Bourke et al., 2006).

Undoubtedly, one of the major limitations of our study was the impossibility to study the 98 patients initially selected for the survey. This problem is commonly faced by researchers dealing with ALS due to the overpowering development of the disease. Another problem that must be considered relevant and limiting for the study was the fact that we hold only two universities in the State of Rio de Janeiro for recruiting patients.

\section{CONCLUSION}

ALS is a progressive and fatal neurodegenerative disease characterized by depletion of the upper and lower motor neurons. The patients develop progressive impairment of muscle strength, speech, swallowing and breathing, with death occurring in average five years after the first manifestations. This study reinforces the previous research findings that suggested that the etiology and path physiology of ALS depends on the interaction of multiple factors. It also provides a clinical and functional overview of 24 patients treated in HUAP and INDC, in order to elucidate the main factors involved with ALS and guide the professionals who deal with this group.

Although there is still no curative therapy for patients with ALS, some progress has been made especially in animal models. The attendance of these patients by an interdisciplinary well trained team is currently the best we can offer in terms of "caring". The multiplicity of guidelines based on consensus should be provided and the goals in the short, medium and long term discussed among professionals.

\section{REFERENCES}

Alcaz, S., M. Jarebinski, T. Pekmezovic, Z. StevicMorinkovic and S. Pavlovic et al., 1996. Epidemiological and clinical characteristics of ALS in Belgrade, Yugoslavia. Acta Neurol. Sand., 94: 264-268. DOI: $10.1111 /$ j.16000404.1996.tb07063.x PMID: 8937538

Borasio, G.D., 2001. Palliative care in ALS: Searching for the evidence base. Amyotroph. Lateral Scler. Other Motor Neuron Disord., 2: S31-35. DOI: 10.1080/113-146608201300079391 PMID: 11465922

Bourke, S.C., M. Tomlinson, T.L. Williams, R.E. Bullock, P.J. Shaw and G.J. Gibson, 2006. Effects of non-invasive ventilation on survival and quality of life in patients with amyotrophic lateral sclerosis. Lancet Neurol., 5: 140-147. DOI: 10.1016/S1474-4422(05)70326-4 PMID: 16426990

Brooks, B.R., R.G. Miller, M. Awash and T.L. Munsa, 2000. World Federation of Neurology Research Group on Motor Neuron Diseases. El Escorial revised: Revised criteria for the diagnosis of amyotrophic lateral sclerosis. Amyotroph. Lateral Scler. Other Motor Neuron Disord., 1: 293-299. DOI: $\quad 10.1080 / 146608200300079536$ PMID: 11464847

Chio, A., G. Logroscino, O. Hardiman, R. Swingler and D. Mitchell et al., 2009. Prognostic factors in ALS: a critical review. Amyotroph. Lateral Scler., 10: 310-23. DOI: 10.3109/17482960802566824PMID: 19922118 
Damiano, A.M., D.L. Patrick, G.I. Guzman, M.J. Gawel and D.F. Gelinas et al., 1999. Measurement of health-related quality of life in patients with amyotrophic lateral sclerosis in clinical trials of new therapies. Med. Care, 37: 15-26. DOI: 10.1097/00005650-199901000-00004 PMID: 10413388

Dengler, R., 1999. Current treatment pathways in ALS: a European perspective. Neurology (Suplem.), 53: S4-10; discussion S20-21. PMID: 10560630

Dupuis, L. and A. Echaniz-Laguna, 2010. Skeletal muscle in motor neuron diseases: Therapeutic target and delivery route for potencial treatments. Curr. Drug Targets, 12: 1250-1261. PMID: 20840067

Faria, D.C., F.M. Favero, S.V. Fontes, A.A.J. Quadros and A.S.B. Oliveira, 2008. Perfil clinico de pacientes com doença do neuronio motor no ambulatorio da Unifesp. Rev. Neurocienci., 16: 189-193.

Gordon, P.H., 2011. Amyotrophic lateral sclerosis: pathophysiology, diagnosis and management. CNS Drugs, 25: 1-15. DOI: 10.2165/11586000000000000-00000 PMID: 21128691

Kraemer, M., M. Buerger and P. Berlit, 2010. Diagnostic problems and delay of diagnosis in amyotrophic lateral sclerosis. Clin. Neurol. Neurosurg., 112: 103-105. DOI: 10.1016/j.clineuro.2009.10.014 PMID: 19931253

Lemoignan, J. and C. Ells, 2010. Amyotrophic lateral sclerosis and assisted ventilation: how patients Odecide. Palliat. Support. Care, 8: 207-213. DOI: 10.1017/S1478951510000027 PMID: 20557668

Orient-Lopez, F., R. Terre-Boliart, D. GuevaraEspinosa and M. Guitart-Bernabeu, 2006. Neurorehabilitation treatment of amyotrophic lateral sclerosis. Rev. Neurol., 43: 549-555. PMID: 17072811

Oliveira, A.S. and R.D. Pereira, 2009. Amyotrophic Lateral Sclerosis: Three letters that change the peoples life. Forever. Arq. Neuropsiquitr, 67: 750782. DOI: 10.1590/S0004-282X2009000400040 PMID: 19722069

Orsini, M., M.R. Freitas, A.S. Oliveira, M.P. Mello and M.A. Chieia et al., 2010. Young-onset sporadic amyotrophic lateral sclerosis. Rev. Neurol., 50: 442-444. PMID: 20387215
Orsini, M., M.R.G. De Freitas, G. Quintanilha, C.H. Melo Reis and V.C. Silveira et al., 2009. Severity and functional ability scale for amyotrophic lateral sclerosis patients: Preliminary results. Am. Acad. Neurol., 72: S72.

Orsini, M., M.R.G. De Freitas, O.J.M. Nascimento, M.P. Mello and C.A. Domingues et al., 2008. Severity and functional scale for amyotrophic lateral sclerosis patients: Description and preliminary results. Rev. Neurocienci., 16: 194203. DOI: $10.4181 /$ RNC.2008.16.194

Rodriguez, G.E., G.M. Gargiulo-Monachelli, M.C. Gonzales-Deniselle and R.E. Sica, 2009. Initial symptoms of amyotrophic lateral sclerosis. Rev. Neurol., 49: 277-278. PMID: 19714560

Sampaio, R.F., M.C. Mancini and S.T. Fonseca, 2002. Scientific production and the professional practice: aspects that limit this integration in physical and ocupational therapy. Rev. Bras. Fisioter., 6: 113118.

Stanich, P., 2006. Suplementaçao nutricional em pacientes com doença do neuronio motor/esclerose lateral amiotrofica. Rev. Neuroci., 14: 72-75.

Traynor, B.J., M.B. Codd, C. Forde, E. Frost and O. Hardiman, 2000. Amyotrophic lateral sclerosis mimic syndromes. A population-based study. Arch. Neurol., 57: 109-113. DOI: 10.1001/archneur.57.1.109 PMID: 10634456

Voltarelli, J.C., 2004. Perspectivas de terapia celular na esclerose lateral amiotrofica. Rev. Bras. Hematol. Hemoter., 26: 155-156. DOI: 10.1590/S151684842004000300002

Williams, B.C., Y. Li, B.E. Fries and R.L. Warren, 1997. Predicting patient scores between the functional independence measure and the minimum data set: development and performance of a FIMMDS "Crosswalk". Arch Phys. Med. Rehabil., 78: 48-54. PMID: 9014957

Zoccolella, S., E. Beghi, G. Palagano, R. Fraddosio and V. Samarelli et al., 2006. Signs and symptoms at diagnosis of amyotrophic lateral sclerosis: A population-based study in southern Italy. Eur. J. Neurol., 13: 789-792. DOI: 10.1111/j.14681331.2006.01384.x PMID: 16834713 